\author{
Military Technical College \\ Cairo, Egypt
}

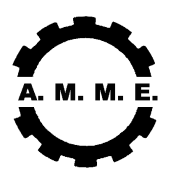

$12^{\text {th }}$ International Conference

on Applied Mechanics and

Mechanical Engineering (AMME)

\title{
THE INFLUENCE OF LASER ASSISTED TURNING PARAMETERS ON CUTTING FORCES - NEW APPROACH
}

BAKER M. H. ${ }^{*}$ YOUSSEF A.M.F. ${ }^{*}$, KOHAIL A.M. ${ }^{*}$, MOUGHITH W.M. ${ }^{*}$

\begin{abstract}
Super alloys have high strength at elevated temperatures, which make them very important to various applications. Such materials are usually difficult to machine at room temperature due to excessive tool wear and poor surface finish. Laser-assisted machining (LAM) offers the ability to those materials more efficiently and economically by providing the local heating of the workpiece before conventional cutting take place. AISI D2 steel is an important example of these super alloys.

The machinability of D2 steel is investigated in this work. This involved the use of crystal laser as heating source together with conventional turning operation. The experimental investigation took into account the cutting forces and tool wear. A comparison between conventional and laser assisted cutting was performed. The effects of variable cutting speed, depth of cut and laser power were investigated. The experimental results showed improvement in cutting conditions and reduction in cutting forces up to $37 \%$.
\end{abstract}

\section{KEYWORDS}

Laser assisted machining (LAM), Turning, Nd-YAG laser, and machinability.

\footnotetext{
* Egyptian Armed Forces.

${ }^{* *}$ Chief of the Academy for specialized studies, Worker's University, Cairo, Egypt.
} 


\section{INTRODUCTION}

Super alloys are widely used in various applications such as aerospace industries, automotive industries and die and mold industries. These materials have high strength and hardness. These lead in difficulty in manufacturing them. In addition to the required high cutting force and the resulted tool wear, it needs more rigid machine tools. Such characteristics lead to high production cost and high investments in addition to the need for subsequent finishing.

AISI D2 tool steel is the focus of this work. It has excellent wear resistance and deep hardening characteristics therefore, it is widely used in the manufacture of blanking and cold forming dies.

\section{PROCESS OVERVIEW}

The concept of assisting material removal during machining by heating materials has been used for many years. Low-grade heat sources such as flame, electrical resistance, induction had been previously used.

using a plasma arc as a heat source was also reported in different researches[1-3]. Although the amount of heat input to the workpiece in plasma arc machining is not limited by reflectivity problems of the metals, it causes extraneous heating to the bulk material, which may cause part distortion and adverse heat affected zones.

In the late 70 s, lasers emerged as a feasible heat source, capable of producing intense heat in a very precise region. Laser assisted machining (LAM) of metals uses a high power laser to provide the local heating of the workpiece prior to material removal cutting tool. Rajagopal et al. [4] experimented with a $14 \mathrm{~kW}$ CO2 laser on titanium and Inconel 718, showing that beam location is important during LAM. LAM provides precise control of deposited energy and heated region, thereby avoiding any undesirable heating of the finished surface. Therefore, it is much more attractive from the view point of ensuring desired subsurface conditions of a machined part.

Advantages of LAM also include the increase in metal removal rates and reduction in the occurrence of chatter and catastrophic tool failure. Different researchers [5-9] have also reported a decrease in the cutting force components, tool wear, and improvement in the capability to cut brittle materials without extensive cracks.

LAM was reported to be used in cutting different materials such as; ceramics, nickel alloys and materials with a tendency to strain hardening like austenitic stainless steels.

In the research carried out by Klocke and Zaboklicki [8] the feasibility of cutting sintered silicon nitride through LAM was proved. Workpiece temperatures was in the range of 1000-1400 C, and the resulting machined surfaces quality was similar to that obtained in diamond grinding. Another work by Lei et al. [10] investigated the 
metallurgical properties of the material in the shear zone. Increased mobility of the rod-like silicon nitride grains, facilitated by a reduction in the viscosity of the intergranular glassy phase at elevated workpiece temperatures lead to the improvement in cutting conditions. Icoropera [6] developed a double-ramp laser profile protocol for LAM of a mullite ceramic to stop the thermal fracture of the workpiece. This fracture was due to of the lower thermal diffusivity, fracture toughness and tensile strength of this material.

LAM was further studied by Icoropera and Shin [6] to cut a partially opaque zirconia, and achieved a forty-fold improvement in the life of the polycrystalline cubic boron nitride tools (PCBN).

LAM of an alumina reinforced aluminum metal matrix composite was studied by Wang [11] reported that LAM reduced cutting forces by $30-50 \%$ and wear of the carbide tool by $20-30 \%$ during the machining of alumina reinforced aluminum metal matrix composite. Salem et. al. [12] characterized the effect of laser power and beam to the tool distance in the machining of hardened XC42 steel and found the cutting forces to be reduced by $80 \%$. In the work by Khan [13] and Dumitrescu et. Al. [14], diode laser was used in cutting AISI D2 steel. Reduction in cutting forces and increase in tool life were observed

\section{OBJECTIVES}

The objective of this experimental investigation is to use Nd-YAG crystal laser to assist the turning of hardened AISI D2 steel. The investigation will observe the variation of cutting forces under different cutting speeds, depth of cut and laser power.

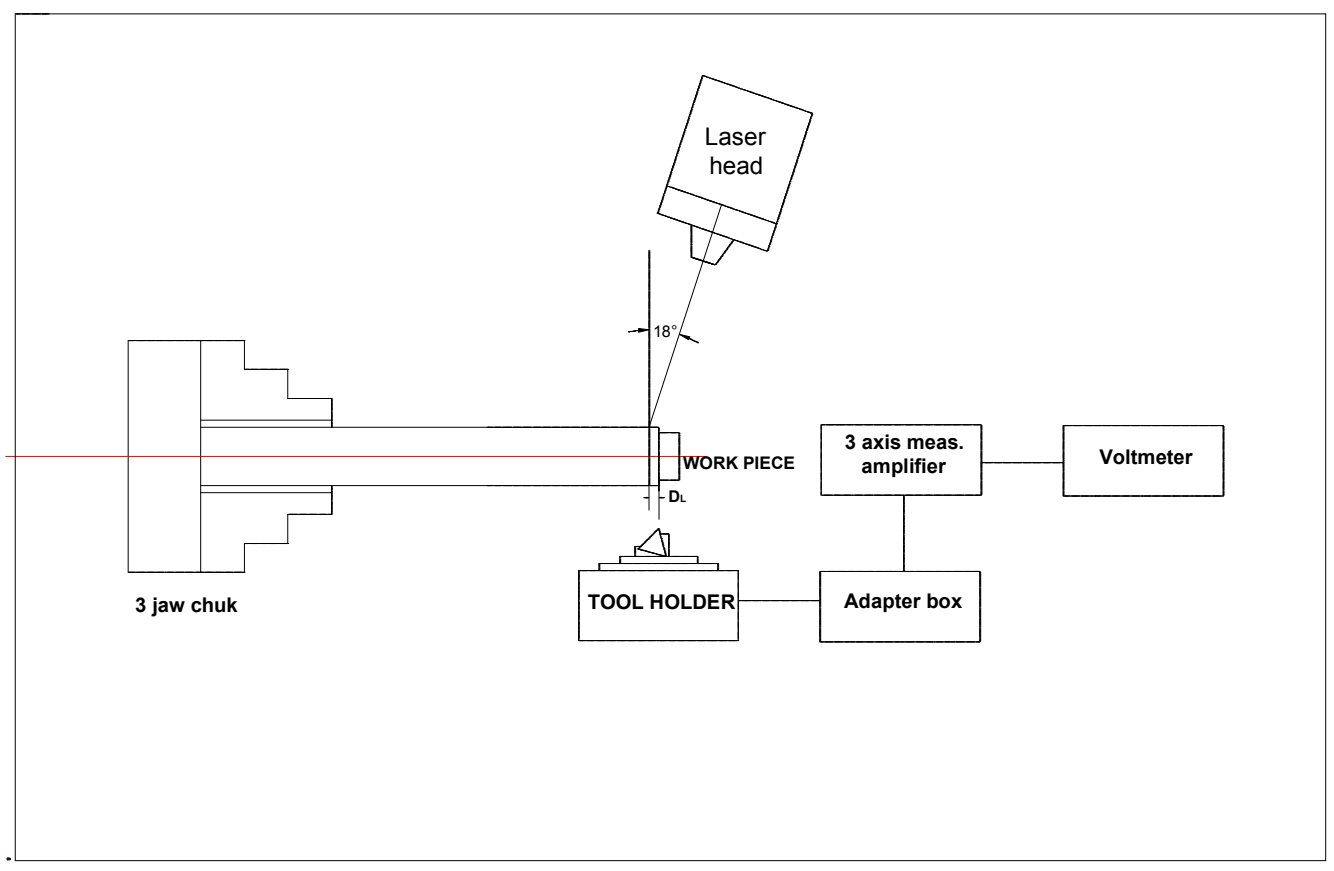

Fig.1. Diagram of the laser assisted turning arrangement 


\section{EXPERIMENTAL SETUP}

The experimental arrangement to investigate the LAM operation (shown in Fig.1) utilized Conventional lathe MDL with $1.3 \mathrm{KW}$ motor power and stepped spindle speed gear box.

The laser source utilized was Nd-YAG pulsed laser JK $702 \mathrm{H}$ by GSI-LUMINICS. The laser generator has with conventional 2 Xe flash lamp and maximum power of 350 $\mathrm{W}$, repetition rate $(0.2-500) \mathrm{Pulse} / \mathrm{sec}$. and Pulse width $(0.5-20) \mathrm{msec}$. The wave length of the beam is $1.06 \mu \mathrm{m}$.

The direction of laser beam is not exactly perpendicular to the axis of the work piece (Fig.2) to prevent the interruption of beam by the chips generated at the cutting point.

The cutting forces were recorded using PHYWE Cutting forces

\section{Fig.3 .}

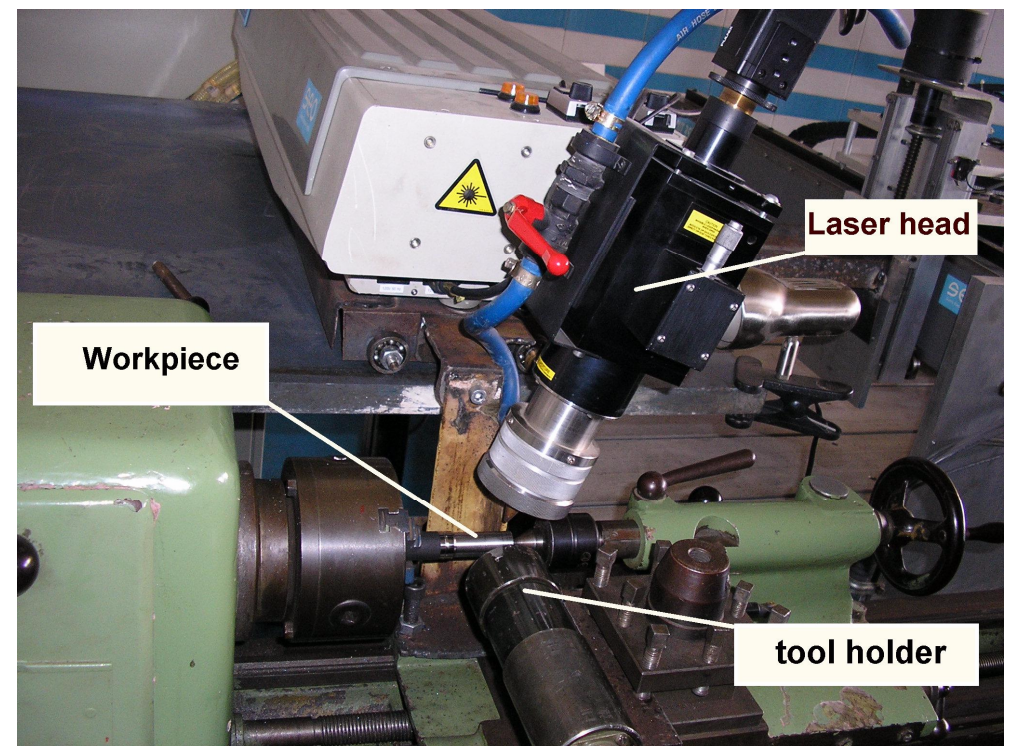

Fig.2.Laser Head inclination

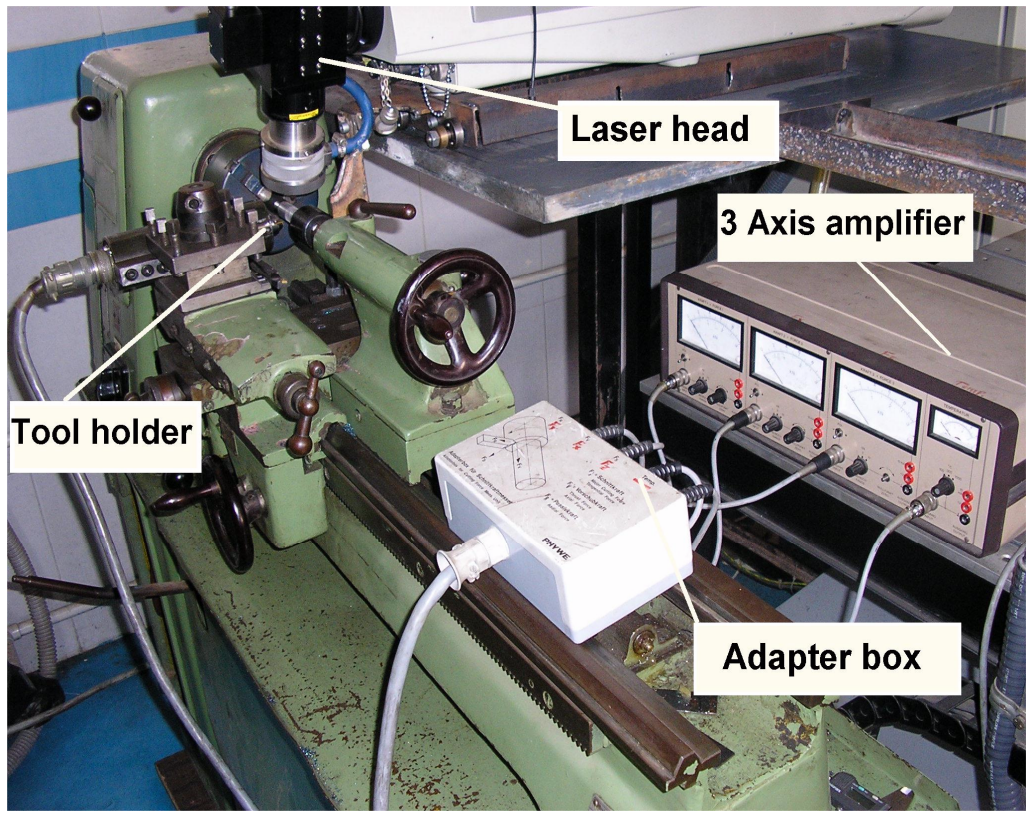

Fig.3. Force measurement system. 


\section{PREPARATION OF SPECIMENS}

AISI D2 steel specimens with length $120 \mathrm{~mm}$ and $20.5 \mathrm{~mm}$ diameter were used. The chemical composition of the steel is illustrated in

Table 1. This steel had initial hardness $\sim 23$ HRC. All specimens were through hardened to hardness $\sim 58 \mathrm{HRC}$. The specimens were machined to a diameter 19 $\mathrm{mm}$. This procedure were performed in order to make sure that any deformations or surface defects either from the raw material or as a result of the heat treatment are eliminated.

Table 1 Chemical composition of D2 tool steel [15]

\begin{tabular}{ccccccc}
\hline Chemical composition & $\mathrm{C}$ & $\mathrm{Mn}$ & $\mathrm{Cr}$ & $\mathrm{Si}$ & $\mathrm{V}$ & $\mathrm{Mo}$ \\
Weight (\%) & 1.55 & 0.4 & 11.8 & 0.3 & 0.8 & 0.8 \\
\hline
\end{tabular}

\section{EXPERIMENTAL CONDITIONS}

The distance between laser spot and tool cutting point (Laser-tool lead) DL is an important parameter to be adjusted. According to the calculations in the work by Salem et. Al. [12],the cutting point must not exceed the radius of the workpiece and adjusted using optic lens as in Fig.1.

During the experiments, the laser spot diameter was $D=1 \mathrm{~mm}$ and beam focusing distance $6 \mathrm{~mm}$. The laser power change is achieved by changing repetition rate while the pulse energy is kept constant at value of 14.2 jules/pulse. Also the pulse width was kept constant at $20 \mathrm{msec}$.

Assist gas was used to protect the laser optics from the fumes and debris resulting from the heating and cutting process. Air was compressed to two bar to achieve the aforementioned task.

The workpiece was laser- preheated to shorten the time required for heating the workpiece during the actual cutting process. The required time for preheating was experimentally determined and found to be $t_{p} \approx 5 \mathrm{sec}$.

Coated carbide tools of grade GC3015 (by SANDVIK®) were used, The tool has nose radius of $0.4 \mathrm{~mm}$ and setting angle of $45^{\circ}$. During the experiment a fresh cutting edge was used each time. 


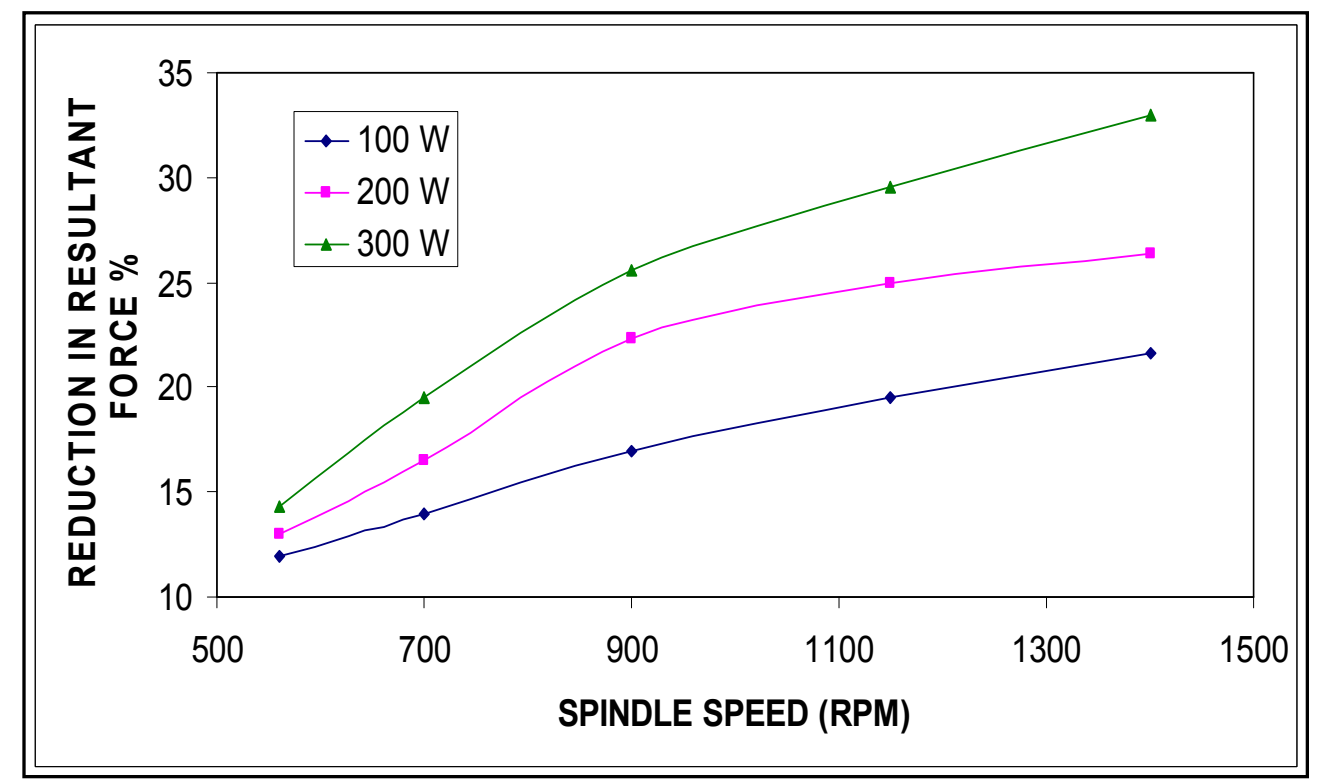

Fig.4. Relation between cutting speed and reduction in cutting forces at different laser power (Depth of cut $0.4 \mathrm{~mm}$.)

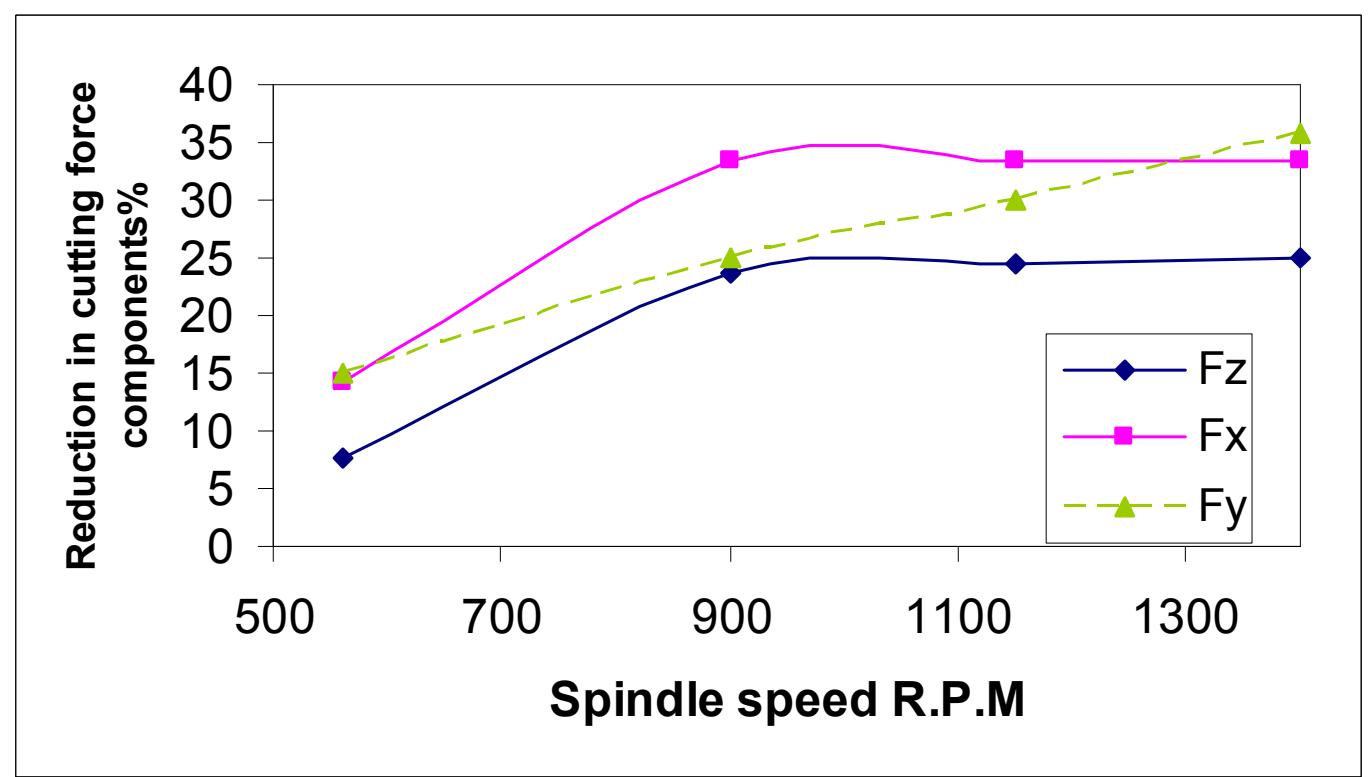

Fig.5. Effect of spindle speed on reduction in cutting forces (Power $300 \mathrm{~W}$, depth of cut $0.4 \mathrm{~mm}$.) 


\section{RESULETS AND ANALYSIS}

\subsection{Relation between Spindle Speed and Cutting Forces}

Comparative experiments of the effect of spindle speed on the reduction in resultant cutting force $\left(F_{\% R}\right)$ at variable laser power are investigated. The feed is $0.072 \mathrm{~mm} / \mathrm{min}$ and depth of cut is $0.4 \mathrm{~mm}$.

The reduction in resultant cutting force $\left(F_{\% R}\right)$ in LAM is varied from $20 \%$ to $33 \%$ for laser powers from 100 to $300 \mathrm{~W}$ at the $1400 \mathrm{rpm}$ as shown in Fig.4. It can be observed from the figure that the reduction in cutting forces percentage increased with the increase of the cutting speed. This may be attributed to the fact that at higher cutting speeds the time required the heated workpiece spot to reach the cutting tool is less. Thus, the temperature drop is less and the workpiece ductility is higher.

The increase in reduction in cutting force components in LAM at 300 Watts as Fig. 5 shows that in different spindle speed. Reduction percentage of the axial cutting force $F_{Z}$ and tangential force $F_{x}$ components are constant above certain cutting speed. While the reduction in radial force $F_{y}$ Continues to increase with the increase of cutting speed. This is due to the softening of workpiece material on the surface layer by the laser beam.

\subsection{Relation between Depth of Cut and Cutting Forces at Variable Laser Power}

The Influence of different cutting depth on resultant force at variable laser power with fixed spindle speed $900 \mathrm{rpm}$ and feed $0.072 \mathrm{~mm} / \mathrm{rev}$ is shown in Fig. 6.

It can be seen from the figure that the resultant cutting force of the conventional turning is higher than the laser assisted turning, This can be attributed to thermal softening by laser.

Fig.7. shows the relation between reduction in resultant cutting force $\left(F_{\% R}\right)$ and the increase of laser power at different depth of cuts. It can be seen from the figure that even with the increase of laser power the degree of force reduction is less at higher depth of cut. This can be attributed to the decrease in the degree of thermal softening by laser with increasing depth of cut. The amount of heat transferred to the workpiece is not sufficient to reach the whole depth of cut. 


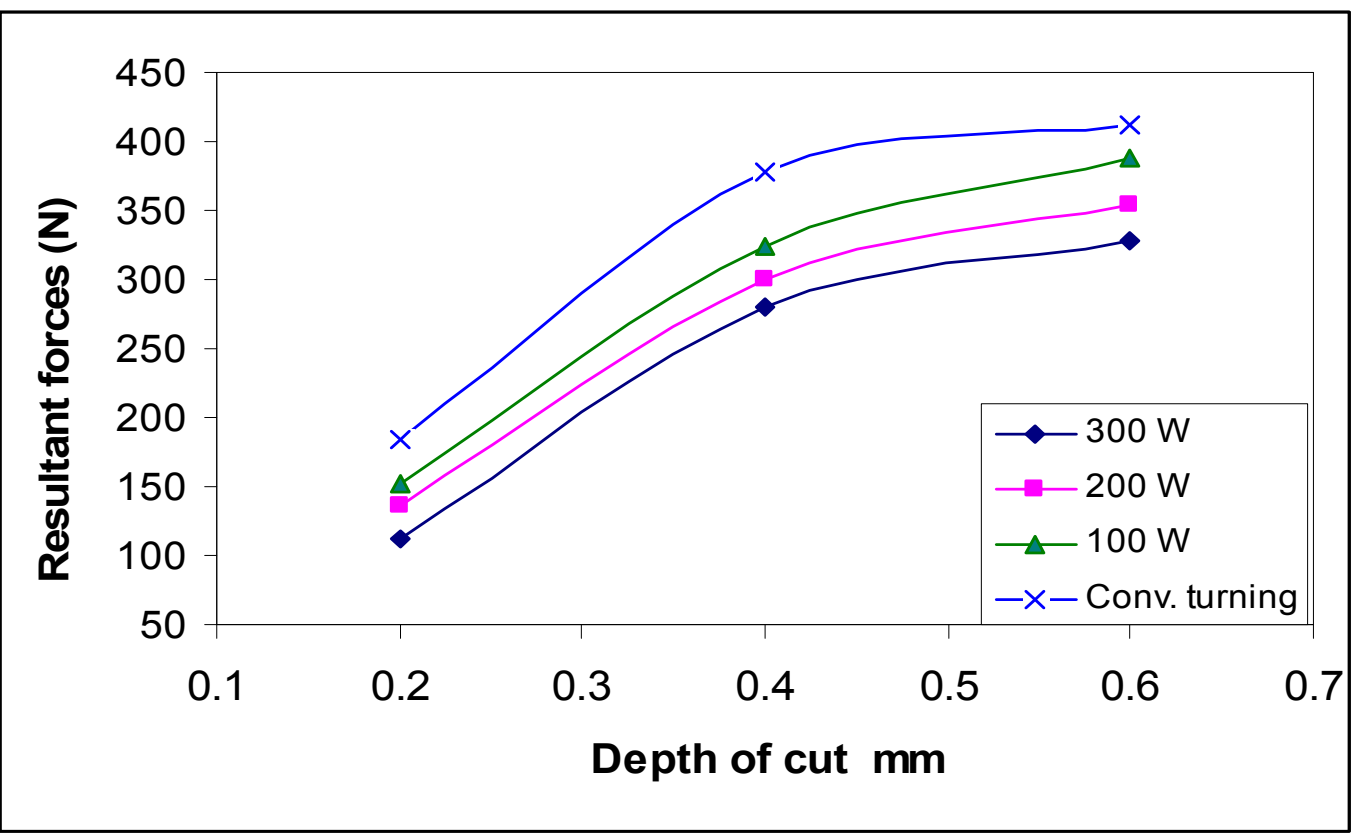

Fig.6. Influence of depth of cut on resultant cutting force at variable laser power at $900 \mathrm{rpm}$

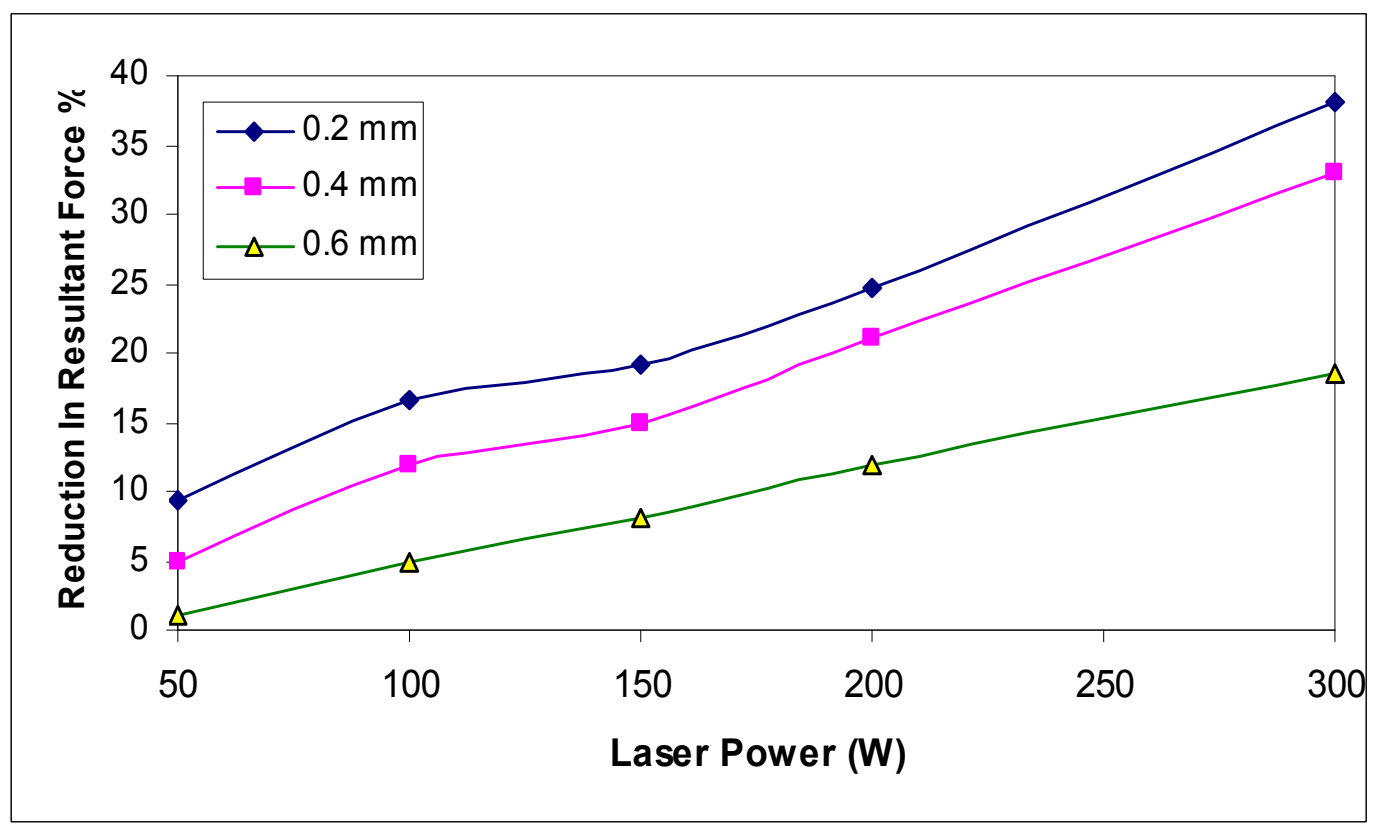

Fig.7. Influence of laser power on reduction in resultant force at different laser powers at $900 \mathrm{rpm}$ 


\subsection{Relation between Laser Power and Reduction in Cutting Forces}

An increase in reduction in cutting force components is observed with the increase of laser power as shown in Fig.8. Reduction in forces can be explained by the increase of temperature with the laser power in the vicinity of the cutting edge, which makes the material more ductile and easy to flow on the face of the cutting edge.

The increase in reduction in cutting force components in radial direction is around 26$35 \%$, in axial direction is $18-25 \%$ and in Tangential direction is around $8-33 \%$.

This increase may result from the increased amount of thermal energy transferred to the workpiece resulting in increase in its temperature which appears in the form of thermal softening.

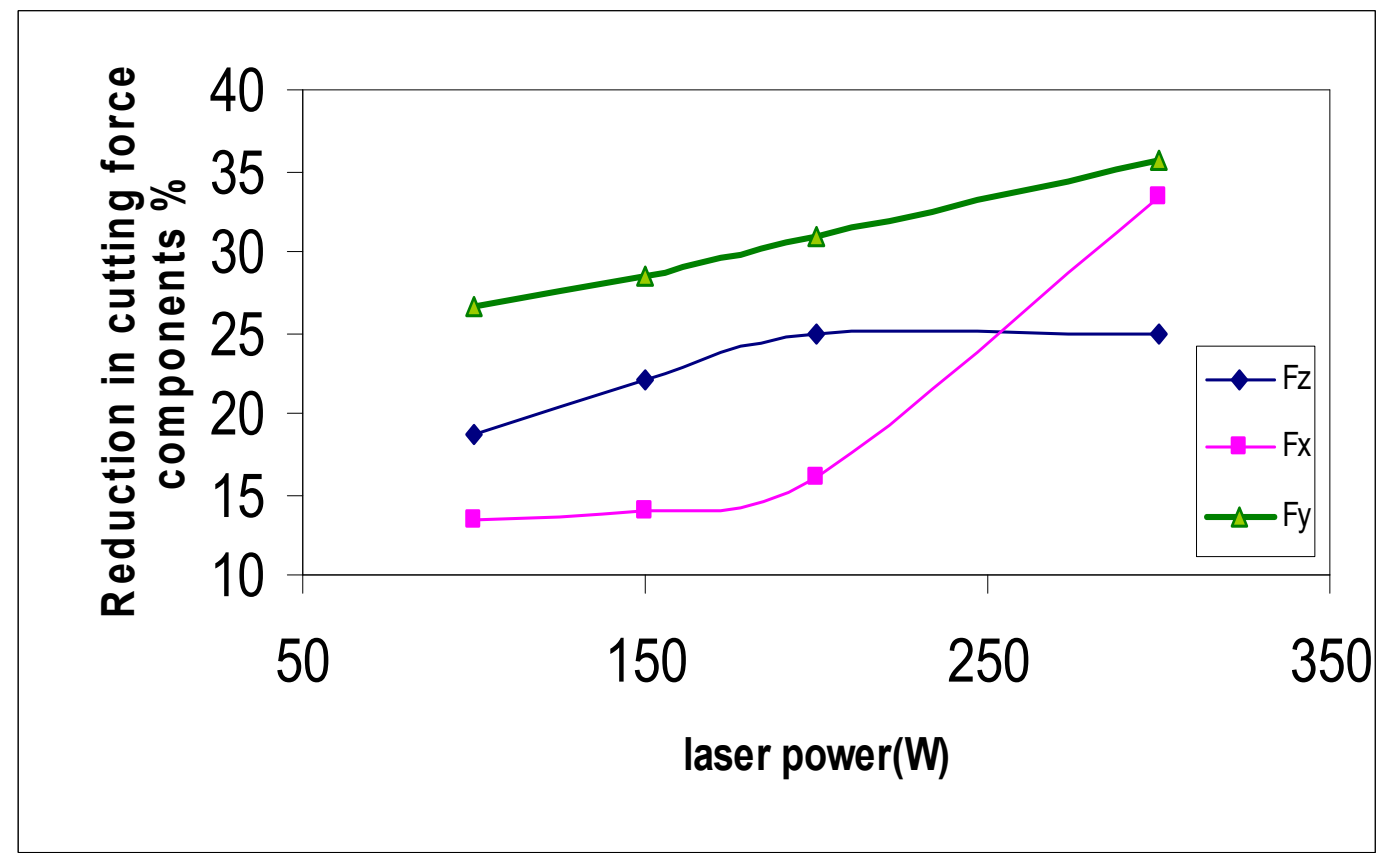

Fig.8. Influence of laser power on reduction in 3 axis forces at depth of cut $0.4 \mathrm{~mm}$ and $1400 \mathrm{rpm}$

\section{CONCLUSIONS}

In this work, Crystal-laser assisted turning process of hardened AISI D2 has been investigated. The results showed decrease in cutting forces over the use of conventional turning due to the thermal softening effect of the laser beam. It was found that with increase of spindle speed the value of $\left(F_{\% R}\right)$ was increased due to the increase in the amount of heat generated from the conventional cutting. The value of $\left(\mathrm{F}_{\% \mathrm{R}}\right)$ was increased by approximately $37 \%$ at $900 \mathrm{rpm}$ for the resultant force. This increased was less at higher depth of cuts due to the fading effect of laser power away from the workpiece surface.

Due to the wave length of the crystal laser, the efficiency of the beam was greater than in previously reported work [13] due to the higher power intensity and absorbability in the metal. 


\section{REFERENCES}

[1] Novak, J.W.," Plasma enhanced machining of difficult to manufacture materials", in Mechanical engineering, Purdue University: West Lafayette, IN. (1995).

[2] Novak, J.W., Y.C. Shin, and F.P. Incropera," Assessment of plasma enhanced machining for improved machinability of Inconel 718", ASME Journal of Manufacturing Science and Engineering 112: p. 125-129. (1997).

[3] Leshock, C.E., J.N. Kim, and Y.C. Shin," Plasma enhanced machining of Inconel 718: modeling of workpiece temperature with plasma heating and experimental results", International Journal of Machine Tools and Manufacture. 41: p. 877-897. (2001).

[4] Rajagopal, S., D.J. Plankenhorn, and V.L. Hill," Machining aerospace alloys with the aid of a 15 kW laser", Journal of Applied Metalworking. 2(3): p. 170184. (1982).

[5] Chryssolouris, G.," Laser assisted machining: an overview", Journal of manufacturing science and engineering, (119): p. 766-769. (1997).

[6] Incropera, F.P.," Laser assisted machining of reaction sintered mullite ceramics", Journal of Manufacturing Science and Engineering 124: p. 875885. (2002).

[7] Incropera, F.P. and Y.C. Shin," Laser assisted machining of magnesiapartially-stabilized zirconia", Journal of Manufacturing Science and Engineering 126: p. 42-51. (2004).

[8] Klocke, F. and A. Zaboklicki, " Laser-Assisted Turning of CeramicsMachining of ceramics and composites". Manufacturing Engineering and Materials Processing, ed. S. Jahanmir, M. Ramulu, and P. Koshy, New York: Taylor \& Francis CRC press. (1999).

[9] Zhu, B.O. and Y. Wang," Experimental research on laser-assisted cutting of GH4169 high temperature alloy", in SPIE. (2002).

[10] Lei, S. and Y.C. Shin," Deformation mechanisms and constitutive modeling of silicon nitride undergoing laser assisted machining", International Journal of Machine Tools and Manufacture. 40: p. 2213-2233. (2000).

[11] Wang, Y.," An investigation of laser assisted machining of Al2O3 particle reinforced aluminum matrix composite", Journal of Materials Processing Technology. 129: p. 268-272. (2002).

[12] Salem, W.B., G. Marot, J.P. Longuemard, and A. Moisan," Laser Assisted Turning during Finishing Operation Applied to Hardened Steels and Inconel 718", in Laser Assisted Net Shap Machining, Institute of manufacturing technology, University of Erlangen Nuremberg. (1994).

[13] Khan, A.R.," Laser Assisted Machining", in Mechanical engineering, McMaster University: Hamilton, On. p. 115. (2002).

[14] Dumitrescu, P., P. Koshy, J. Stenekes, and M.A. Elbestawi," High-power diode laser assisted hard turning of AISI D2 tool steel", International Journal of Machine Tools and Manufacture. In press: p. corrected proof. (2006).

[15] American Iron and steel institute Material standard", American Iron and steel institute. (2004). 